\title{
Nadir Görülen Bir Paraneoplastik Sendrom: Sweet Sendromu
}

\author{
A Rare Paraneoplastic Syndrome: Sweet Syndrome \\ Dilek GÜNEY', Mehtap ŞAHIN²
}

\author{
${ }^{1}$ Bayat Devlet Hastanesi İç Hastalıkları, Çorum,Türkiye \\ ${ }^{2}$ T.C. Hitit Üniversitesi Erol Olçok Eğitim ve Araştırma Hastanesi İç Hastalıkları, Çorum,Türkiye
}

\begin{abstract}
Özet
Paraneoplastik Sendrom; primer tümöre veya metastazlarına ait bir etki sebebi ile oluşmayan ancak, tümörün varlığına bağımlı olarak gelişen belirti ve bulgulardan oluşan klinik tablo olarak adlandırılır. Paraneoplaziler varlığı bilinen bir tümörün seyri sırasında görülebildiği gibi, klinik olarak ortaya çıkmamış gizli bir tümörün ilk ve tek belirtisi olarak primer kanserin erken evrede tanınmasına yardımcı olabilmektedir. Akut febril nötrofilik dermatoz olarak da adlandırılan Sweet Sendromu; ani başlangıçlı, ağrılı, inflamatuar papül veya nodüllerden oluşmuş eritemli plaklar, ateş, eklem ağrısı, periferik lökositoz ve cildin dermis tabakasında yoğun nötrofil infiltrasyonu ile karakterize nadir görülen tekrarlayan inflamatuar bir cilt hastalığıdır. Hastalık; inflamatuar bağırsak hastalığı, enfeksiyonlar, ilaçlara sekonder, maligniteye sekonder(paraneoplastik) olarak gözlemlenebilmektedir. Bu yazımızda akut gelişen döküntü ve ateş şikayetleri ile başvurduğu hastanede Sweet Sendromu ön tanısı ile interne edilen, ardından yapılan etiyolojik araştırmasında metastatik akciğer karsinoid tümör tanısı konulan 69 yaşında erkek hasta ile ilgili bir olgu sunmayı amaçladık.
\end{abstract}

Anahtar Kelimeler: Sweet Sendromu, Paraneoplastik Sendrom, Akciğer Kanseri

\begin{abstract}
Paraneoplastic Syndrome; It is called a clinical picture that does not occur due to an effect of the primary tumor or its metastases, but consists of signs and symptoms that develop depending on the presence of the tumor. Paraneoplasias can be seen during the course of a tumor with a known presence, as well as being the first and only sign of a hidden tumor that has not emerged clinically, it can help to identify primary cancer at an early stage. Sweet's Syndrome, also called acute febrile neutrophilic dermatosis; It is a rare, recurrent inflammatory skin disease characterized by sudden onset, painful, inflammatory papules or nodules with erythematous plaques, fever, joint pain, peripheral leukocytosis and intense neutrophil infiltration in the dermis layer of the skin. Illness; It can be observed as inflammatory bowel disease, infections, secondary to drugs secondary to malignancy (paraneoplastic). In this article, we aimed to present a case of a 69-year-old male patient who was hospitalized with acute rash and fever with a pre-diagnosis of Sweet Syndrome and was diagnosed with metastatic lung carcinoid tumor in the following etiological investigation.
\end{abstract}

Keywords: Sweet Syndrome, Paraneoplastic Syndrome, Lung Cancer

Yazışma Adresi: Mehtap ŞAHİN,T.C. Hitit Üniversitesi Erol Olçok Eğitim ve Araştırma Hastanesi/Çorum,Türkiye Telefon: 05449380106, Mail: mehtapcatalkaya@gmail.com

ORCID No (Sirasıyla): 0000-0003-1416-8122, 0000-0001-8495-2858

Geliș Tarihi: 16.10.2020

Kabul Tarihi: 25.11.2020

DOI: $10.17517 /$ ksutfd. 811448 


\section{GIRIŞ}

Akciğer kanseri dünyada ve ülkemizde sık görülmekte olup, mortalitesi yüksek olan kanserlerden biridir. Klinik şüphe ile tanısı konulan akciğer kanseri, paraneoplastik durumlarla birlikte de kendini göstermektedir (1). Karsinoid tümörler akciğerlerde nadir olarak görülmektedir (2). Akciğer karsinoid tümörlerin çoğu tipik karsinoid tümörler olarak gençlerde meydana gelip, yavaş büyüme sergilerken; atipik akciğer karsinoid tümörleri ise agresif bir şekilde organ ve lenf metastazı eğilimi gösterip, prognozu kötüdür (3). Primer tümöre veya metastazlarına ait bir etki sebebi ile oluşmayan, ancak tümörün varlığına bağımlı olarak gelişen belirti ve bulgulardan oluşan klinik tablo paraneoplazi olarak adlandirılır (4). Bu durum sıklıkla tümör hücreleri tarafından salgılanan hümoral etkenler ya da tümör hücrelerine karşı gelişen immün yanıt sonucu ortaya çıkmaktadır. Paraneoplaziler, varlığı bilinen bir tümörün seyri sırasında görülebildiği gibi, klinik olarak ortaya çıkmamış gizli bir tümörün ilk ve tek belirtisi olabilir ve bu sayede primer kanserin erken evrede tanınmasina yardımcı olabilmektedir (5). Akut febril nötrofilik dermatoz olarak da bilinen Sweet Sendromu ilk kez 1964 yılında Robert D. Sweet tarafından tanımlanmıştır. Hastalık ağrılı inflamatuar papül ve nodüllerden oluşmuş eritemli plaklar, ateş, nötrofilik lökositoz ve dermiste yoğun nötrofil infiltrasyonu ile karakterizedir (6-8).
Sweet Sendromu çoğunlukla idiopatikolarak ortaya çıkmakla birlikte vakaların bir kısmı enfeksiyonlar, ilaçlar, otoimmün hastalıklar ve neoplastik hastalıklar ile ilişkilidir (9). Sweet Sendromlu hastaların \%20'si malignite ile ilişkilidir. Malign hastaların \%85'inden fazlası bir hematolojik hastalığa sahiptir. Sıklıkla Akut Myleoid Lösemi ile birlikte ve daha az sayıda da lenfomalarla birlikte ilişkilidir. En sık görülen solid tümörler; gastrointestinal sistem, genitoüriner kanal tümörleri ve meme karsinomlarıdır (10-14). Nadir olarak akciğer kanserine bağlı paraneoplastik geliştiği gözlemlenen Sweet Sendromunda ilk basamak tedavi glukokortikoid olup, bu tedaviye dramatik yanıt gözlemlenmektedir. Hastalarda etiyolojik araştırma mutlaka yapılmalı olası malignite gözden kaçırılmamalıdır.

\section{OLGU SUNUMU}

69 yaşında erkek hasta yaklaşık 10 gündür devam eden vücutta kızarıklık, kaşıntı, döküntü ve ateş şikâyeti olması üzerine poliklinikte değerlendirilerek dahiliye kliniğine yatırıldı. Hastadan alınan anamnezde yaklaşık 2 yıldır Diyabetes Mellitus, Hipertansiyon tanılarının mevcut olduğu ve sigara kullanmadığı öğrenildi. Hastanın bakılan hemogramında lökosit/WBC değeri 45.860 idi ve nötrofil hakimiyeti mevcuttu. Hastaya yapılan periferik yaymasında parçalı hakimiyeti, eozinofili mevcut olup atipik hücre saptanmadı (Şekil $1 \mathrm{a} / \mathbf{1 b} / \mathbf{1 c})$.
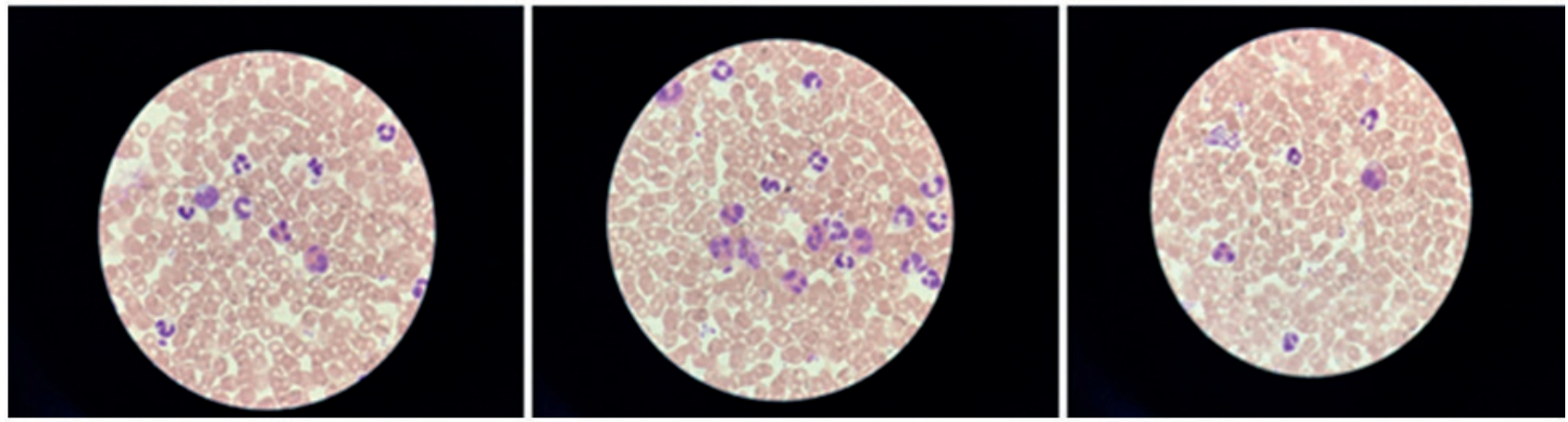

Şekil 1a/1b/1c. Periferik yaymada eozinofili ve nötrofili (normokrom makrositter eritrositler, trombositler küme yapmış yeterli sayıda, bant formasyonunda nötrofili)
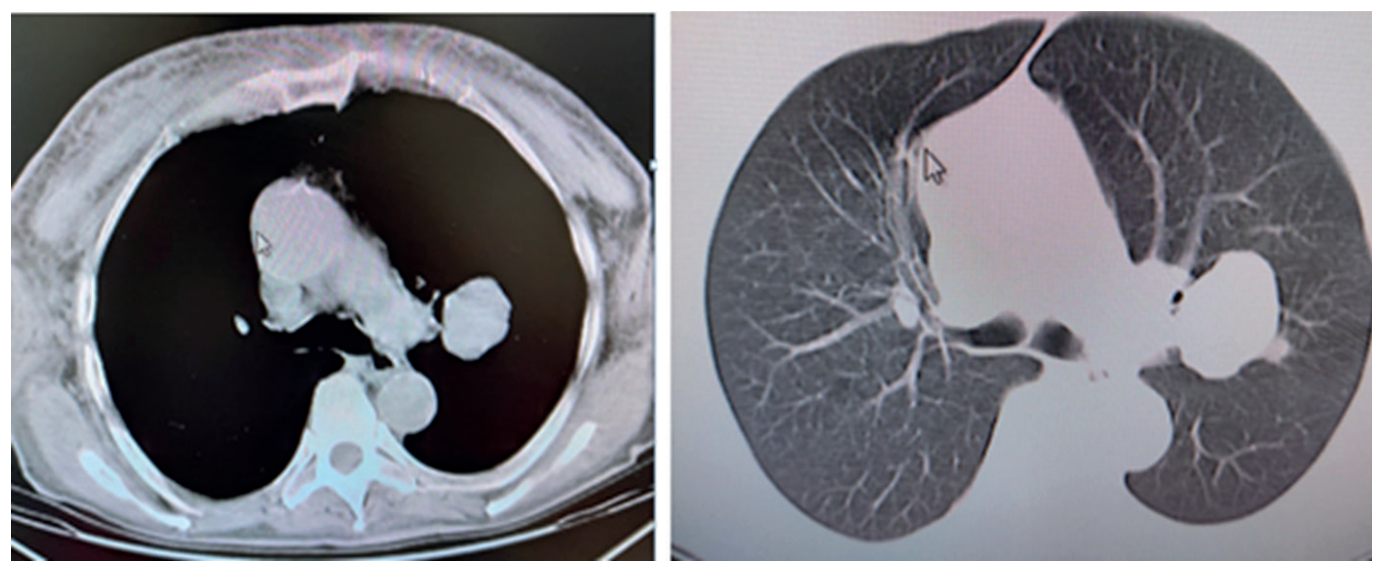

Şekil 2 a/b. Akciğer tomografisi kitlesel lezyon görüntüsü(sol akciğer üst lob posterior segmentte hafif lobüle konturlu yaklaşık $43 * 35 \mathrm{~mm}$ boyutlarında yumuşak doku kitlesi) 
Ateși olan hastaya intravenöz antibiyotik tedavisi başlandi. Hasta cildiye birimi ile konsülte edildi. Hastaya Sweet Sendromu ön tanıs ile cilt biyopsisi yapılarak sonrasında intravenöz steroid tedavisi başlandı. Ayrıntılı etiyolojik değerlendirme için çekilen akciğer grafisinde kitle şüphesi mevcut olan hastaya toraks tomografisi çekildi. Çekilen tomografide sol akciğer üst lob posterior segmentte hafif lobüle konturlu yaklaşık $43^{*} 35 \mathrm{~mm}$ boyutlarında yumuşak doku kitlesi (Şekil 2 a/b) saptanan hastaya ardından bronkoskopi yapıldı.

Takipleri devam eden geliş kreatinin değeri $1,2 \mathrm{mg} / \mathrm{dL}$ olan hastada hızlı bir şekilde akut böbrek yetmezliği tablosu gelişti. Anüriye giren kreatinin değeri hızlı bir şekilde 4,6 mg/ dL'ye yükselen hasta hemodiyalize alındı (Tablo1). Steroid tedavisinin birinci haftasında hasta klinik ve laboratuar olarak düzelmeye başladı. Hastanın döküntülerinde belirgin bir düzelme saptandı (Şekil 3a/b/c).

Hastanın bronkoskopik biyopsi sonucu;" tümör hücrelerinde PAN, CK, Synaptofizin, Kromogranin ve S100 ile kuvvetli boyanma görülen ki-67 proliferasyon indeksi \%1-2" olarak değerlendirilen "atipik karsinoid tümör" olarak raporlandı. Karaciğer enzimlerinde ılımlı yükselme nedeni ile çekilen batın ultrasonunda hastada karaciğer sağ lobda kitle
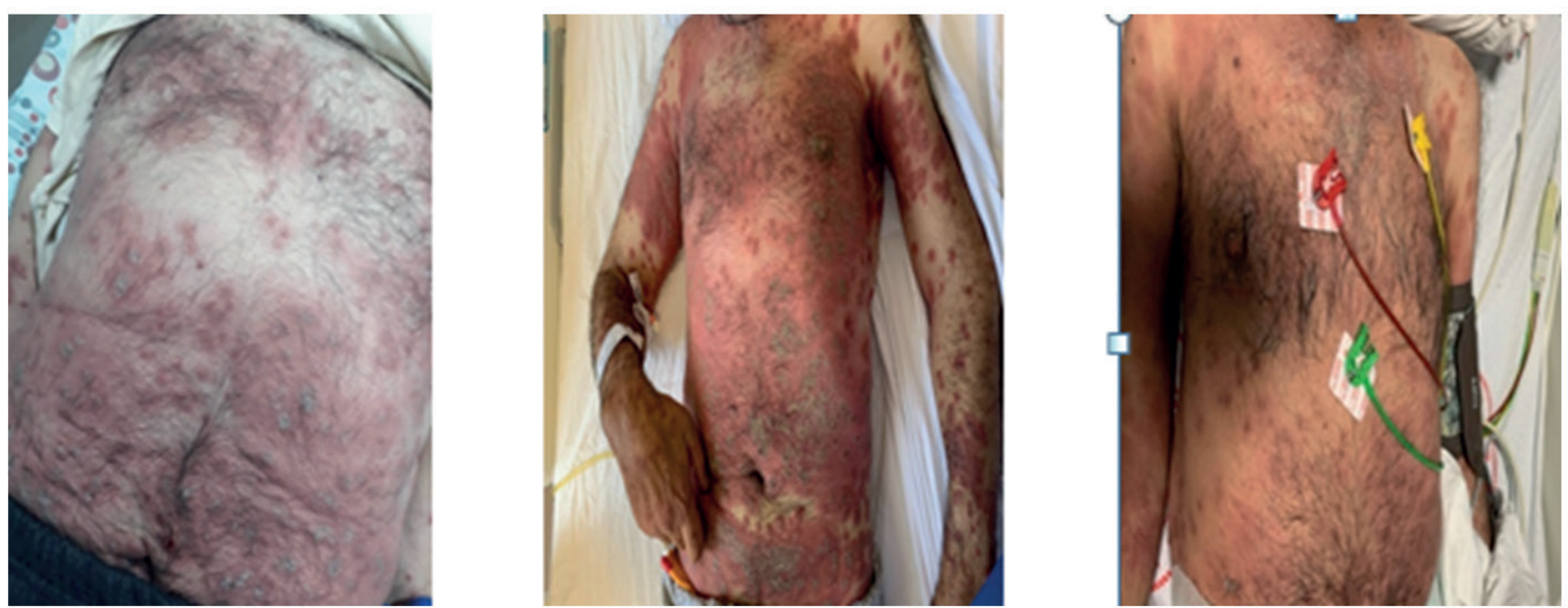

Şekil 3a/b/c. Hastaneye başvuru görünümü, tedavinin üçüncü günü görünümü, tedavinin 1 . haftası görünümü

Tablo 1. Hastanın laboratuvar parametreleri

\begin{tabular}{|c|c|c|c|c|c|c|c|}
\hline & 21.5.2020 & 28.5.2020 & 29.5.2020 & 30.5 .2020 & 30.5 .2020 & 31.5 .2020 & 2.6.2020 \\
\hline Glukoz (AKȘ) & 162 & 193 & 143 & 106 & 133 & 120 & 146 \\
\hline Üre & 84 & 237 & 173 & 135 & & 105 & 40 \\
\hline Kreatinin & 1,2 & 4,6 & 3,6 & 2,4 & 2,1 & 1,1 & 0,6 \\
\hline AST & 44 & 25 & 40 & 57 & 50 & 51 & 37 \\
\hline ALT & 70 & 44 & 43 & 53 & 52 & 60 & 57 \\
\hline Total Bilirubin & 0,60 & 0,68 & 0,64 & 0,60 & 0,62 & 0,56 & 0,87 \\
\hline Direkt Bilirubin & 0,14 & 0,20 & 0,13 & 0,17 & 0,21 & 0,16 & 0,25 \\
\hline $\mathrm{LDH}$ & 363 & & 725 & 413 & 360 & 444 & 412 \\
\hline $\mathrm{Wbc}$ & & 45860 & 39610 & 29190 & & 22350 & 20420 \\
\hline $\mathrm{Hb}$ & & 14,1 & & & & & \\
\hline Nötrofil\% & & 76,9 & & & & & \\
\hline Monosit\% & & 1,27 & & & & & \\
\hline Lenfosit $\%$ & & 3,1 & & & & & \\
\hline Eozinofil\% & & 16,5 & & & & & \\
\hline Trombosit & & 357000 & & & & & \\
\hline Prokalsitonin & & 1,64 & & & & & \\
\hline Sedimentasyon & & 2 & & & & & \\
\hline C-Reaktif protein & & 43,5 & & 22,5 & & & 12 \\
\hline $\mathrm{HbA1c}$ & & 6,1 & & & & & \\
\hline
\end{tabular}


gözlemlendi. Hastaya PET-CT çekildi. PET-CT görüntülemesinde "karaciğerde hipodens lezyonları görülen metastaz? İkincil primer lezyon? " olarak değerlendirilen hastaya karaciğer Tru-cut biyopsisi yapıldı. Karaciğer biyopsi sonucu Synaptofizin, Kromogranin ile diffüz kuvvetli boyanma izlenen, ki-67 proliferasyon indeksi $\% 1$ olarak değerlendirilen "atipik karsinoid metastazı" olarak raporlandı. Hastanın mevcut Sweet Sendromu malignite ile ilişkilendirildi. Metastatik akciğer karsinoid tanılı hasta onkoloji birimi ile konsülte edilerek kemoterapi tedavisine başland.

\section{TARTIŞMA}

Akut nötrofilik dermatoz olarak bilinen Sweet Sendromu 1964 yilında ilk defa Robert D. Sweet tarafından etiyolojisi bilinmeyerek tanımlanmış olup, genellikle aniden $38^{\circ} \mathrm{C}$ üzeri ateş, deride ağrılı, nodüllerden oluşmuş hassas plaklar ve histopatolojik olarak vaskülit bulgusu olmaksızın dermiste yoğun nötrofil infitrasyonu ile karakterizedir (15-17). Sweet Sendromu nadir görülen deri hastalıkları arasındadır. Ekstrakutanöz tutulumu genellikle eklem ve gözde lokalizedir. Hastalarda artralji, konjonktivit, sklerit ve iritis görülebilir. Aynı zamanda lenf bezleri, dalak, karaciğer ve akciğer tutulumları literatürde de görülmektedir. Etiyolojik olarak sistemik rahatsızlıklarda, malignitelerde, otoimmün hastalıklarda, hamilelikte, aşı sonrası, iltihabi bağırsak hastalıklarında veya enfeksiyonlarda, paraneoplastik ve ilaca bağımlı olarak karşımıza çıkmaktadır $(18,19)$. Patofizyolojisi net olarak bilinmemekle beraber, bir kısım bilim adamları tarafından bakteriyel, viral ve tümoral antijenlere karşı kompleman sistem reaksiyonu oluşmadan meydana gelen immünolojik bir reaksiyon olduğu varsayılmaktadır. Alerjen stimülasyonu sonucu immün kompleks oluşur, daha sonra deride birikmesi nedeniyle, inflamatuar hücrelerde aktifleşme ve inflamatuar mediyatörler ve sitokinlerin salınımı gerçekleşir. Serumda özellikle IL-6 (hastalık hissine ve ateşe sebep olur) ve G-CSF (kemik iliğinde nötrofilik granülositlerin oluşumunu ve aktivasyonunu indükler) parametrelerinde artış gözlemlenir. Bu sebeple yeni yapılan çalışmalarda miyeloproliferatif hastalıklarda verilen G-SCF’in doza bağlı Sweet Sendromu indüklediği gözlemlenmiştir. Sweet Sendromunda diyagnoz majör ve minör kriterlere göre konulmaktadır. İki majör ve iki minör kriter muhakkak olmalıdır (20).

\section{Majör}

1. Ani başlangıçlı acılı eritematöz nodüller veya plaklar.

2. Histopatoloji olarak; yoğun nötrofilik sızma, lökositoklastik vaskülit olmaksızın

\section{Minör}

\section{Ateş> $38^{\circ} \mathrm{C}$}

4. Altta yatan hematolojik veya visseral malignite, inflamatuar hastalık, gebelik veya öncesinde üst solunum yolu enfeksiyon, gastrontestinal enfeksiyon geçirme öyküsü, aşılama öyküsü ki

5. Sistemik kortikosteroidler ile tedaviye mükemmel tep-
6. Laboratuvar testlerindeki anormallikler (dörtte üçü): eritrosit sedimantasyon hızı $>20 \mathrm{~mm} / \mathrm{s}$; yüksek C-reaktif protein, lökositler $>8000$, >\% 70 nötrofili (21).

Tedavide sistemik prednizon 30-60 mg/gün başlanıp 4

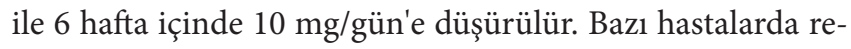
kürrensleri engellemek için 10-30 mg dozlarında 2 ile 3 aya kadar tedavi uygulamak gerekebilir (22). Eğer tedaviye cevap alınamazsa indometazin, siklosiporin veya dapson alternatif olarak verilebilir (23). Vakamızda; nadir görülen Sweet Sendromu yine nadir olarak görülen karaciğer metastazlı akciğer nöroendokrin tümörüne bağlı paraneoplastik olarak karşımıza çıkmaktadır. Malignite ilişkili Sweet Sendromu \%21 oranında görülmekte olup, bunun $85 \%$ i hematoloji hastalıklar ve $\% 15$ i de solid tümörlerdir. Solid tümörler genellikle ürogenital traktadır (24).

Pubmed üzerinden günümüze kadar yapılan literatür taramasında; akciğer maligniteli Sweet Sendromu nadir olup, toplam 8 tane Sweet Sendrom tanılı vakayı görmekteyiz $(23,25-31)$.

2013 yılında yayınlanan bir makalede; 1996 yılında Multiple Myelom tanısı alan, aynı zamanda Sweet Sendromu eşlik eden ve 2007 yılında nadir olarak görülen akciğer nöroendokrin tümörü gelişen iki malignite tanısı alan bir hastanın vakası sunulmuştur ki; 11 yıl sonra hastada nöroendokrin tümör gelişmiştir (25). İkinci nöroendokrin akciğer malignite vakası da bizim hastamızda karaciğer metastazlı akciğer nöroendokrin tümörüne bağlı paraneoplastik Sweet Sendromu olarak karşımıza çıkmıştır. Nöroendokrin tümörler akciğerlerde nadir olarak görülmektedir (32). Embriyonik nöral tüpten organlara göç eden hücreler sonucunda oluşmaktadır. Karsinoid tanımı ilk olarak gastrointestinal trakt için kullanılmış olup, daha sonra akciğerler için de tanımlanmıştır. Gastrointestinal traktan sonra lokalizasyon açısından nöroendokrin tümörler ikinci sıra olarak akciğerlerde olup, akciğer tümörlerinin \%1 ini kapsamaktadır (33). Nöroendokrin tümörler rölatif benign karsinoid olarak görülebildiği gibi aşırı agresif küçük hücreli akciğer kanserleri olarak da görülebilir. Tümör lokalizasyonu, boyutu ve büyüme hızına bağlı olarak farklı semptomlar gösterir, Santral yerleşimde öksürük, hemoptiz, bronşiyal obstrüksiyon oluşabilir. Hastaların \%30 u asemptomatik olabilir (3). Nikotin kullanımı ile karsinoid tümör ilişkilendirilememiştir. Akciğer karsinoid tümörlerin çoğu tipik karsinoid tümörler olarak gençlerde meydana gelip, yavaş büyüme sergilerken; atipik akciğger karsinoidleri ise agresif bir şekilde organ ve lenf metastazı eğilimi gösterip, prognozu kötüdür. Erken tanı sonrası cerrahi rezeksiyon sonrası 5 yıllık ve 10 yıllık yaşam süresi $\% 80$ dir. $\mathrm{Bu}$ nedenle erken diyagnoz ve kanserin evrelerinin teşhisi önemli bir rol oynamaktadır (34).

Vakada; semptom olarak yalnızca nadir görülen Sweet Sendromu şikâyeti ile kliniğe gelen hastamızda (herhangi bir pulmoner şikâyeti olmamasına rağmen) tarama sonrası daha da nadir görülen karaciğer metastazlı akciğer nöroendokrin tümörü tanısı bulunmuştur. Bu vaka bize Sweet Sendromu'nun sık görülen enfeksiyöz hastalıklardan nadir görülen 
hastalıklara kadar geniş bir skalada kendisini gösterebildiğini ve Sweet Sendrom'lu hastalarda prognoz açısından ileri tetkiklerin gerekliliğini göstermektedir. Steroid tedavisi ile kısa sürede iyileşme gözlemlense de, ayrıntılı etiyolojik değerlendirme için ileri tetkikler önemli ve vazgeçilmezdir.

\section{Çıkar Çatışması Beyanı}

Makale yazarları aralarında herhangi bir çıkar çatışmasının olmadığını beyan ederler.

\section{Araştırmacıların Katkı Oranı Beyan Özeti}

Yazarlar makaleye eşit katkı sağlamış olduklarını beyan ederler.

\section{KAYNAKLAR}

1. Brambilla E, Travis WD. World Cancer Report. In: Stewart BW, Wild CP (Eds), World Health Organization, Lyon 2014

2. Pelosi G, Papotti M, Rindi G, Scarpa A. "Unraveling tumor grading and genomic landscape in lung neuroendocrine tumors." Endocrine pathology 2014; 25(2):151-164.

3. Kaifi JT, Kayser G, Ruf J, Passlick B. "The diagnosis and treatment of bronchopulmonary carcinoid." Deutsches Ärzteblatt International 2015;112 (27-28): 479.

4. Okutur K, Demir G. " Paraneoplazi kavrami/Concept Paraneoplasia." Turkderm 2013;47(2): 59.

5. Akyay ÖZ, Selek A, Tarkun İ. "Akciğer Kanseri, Endokrinopatiler ve Paraneoplastik Sendromlar." Bulletin Of Thoracic Surgery/Toraks Cerrahisi Bülteni 2015; 9(4).

6. Wolff K, Goldsmith LA, Katz SI, Gilchrest BA, Paller AS, Leffell DJ. Fitzpatrick's dermatology in general medicine, 2 volumes. Transplantation, 2008; 85(654).

7. Cohen PR, Sweet's syndrome-a comprehensive review of an acute febrile neutrophilic dermatosis. Orphanet journal of rare diseases, 2007; 2(1): 34.

8. Güneş Bılgılı S, Karadağ AS, Çalka Ö, Bayram İ. Sweet Syndrome: Clinical And Laboratory Findings Of 31 Cases. Turkderm-Archieves Of The Turkish Dermatology And Venerology, 2013; 47(1): 33-38.

9. Özuğuz P, Kaçar SD, Terzili M, Celep BR, Yavaş BD.Elin nötrofilik dermatozu. Pamukkale Tip Dergisi, 2014; 2: 147-150.

10. Chung VQ, Moschella SL, Zembowicz A, Liu V. Clinical and pathologic findings of paraneoplastic dermatoses. Journal of the American Academy of Dermatology, 2006; 54(5): 745-762.

11. Stone SP, Buescher LS. Life-threatening paraneoplastic cutaneous syndromes. Clinics in dermatology, 2005; 23(3): 301-306.

12. Schiller M, Böhm M, Hensen P, Riemann H, Luger TA, Nashan D. Dermatomyositis associated with malignant melanoma-A marker of poor prognosis? Journal of the American Academy of Dermatology, 2006; 54(2): 221-226.

13. Akı T, Karıncaoğlu Y, Özcan H, Seyhan ME, Kalaycı B, Karadağ N. Büllöz lezyonların eşlik ettiği idiyopatikSweet sendromu: Olgu tartışması. Journal of Inonu University Medical Faculty, 2004, 11(4), 255-258

14. Yavuz E, Yeşilova Y, Sula B. Paraneoplastik Dermatozlar. Med Bull Haseki 2010;48:61-67

15. Sweet RD An acute febrile neutrophilic dermatosis. British Journal of Dermatology 1964, 76: 349-356.

16. Thompson DF, Montarella KE. Drug-induced Sweet'ssyndrome. Annals of Pharmacotherapy 2007; 41: 802-811.
17. Guarnerı C,La Greca S, Curatolo S, Vaccaro M, Cannavo SP. Sweet's syndrome and erythema nodosum in patient with cystitis caused by Klebsiella pneumoniae. Giornale italiano di dermatologia e venereologia, 2002; 137(5): 331-333.

18. Vignon-Pennamen MD. The extracutaneous involvement in the neutrophilic dermatoses. Clinics in dermatology, 2000; 18(3): 339-347.

19. Von den Driesch P. Sweet's syndrome (acute febrile neutrophilic dermatosis). Journal of the American Academy of Dermatology, 1994; 31(4): 535-556.

20. Orfanos-Garbe, Therapie der Hautkrankheiten, 2. Auflage, 2002, S. 447-448

21. Villarreal-Villarreal CD, Ocampo-Candiani J, Villarreal-Martínez A. Sweetsyndrome: a review and update. ActasDermo-Sifiliográficas (English Edition), 2016; 107(5): 369-378.

22. Alibaz Oner F, Unalan N, Ergüney M, Turgut Erdemir A, Turan E. Akut Febril notrofilik dermatoz (Sweet Sendromu). İstanbul Tip Dergisi 2005; 2: 47-49

23. Ara1 H, Rino Y, Yamanaka S, Suganuma N, Yukawa N, Wada N et al. Lung Cancer Associated With Sweet's Syndrome: Report Of A Case. Surgery Today, 2008; 38(7): 639-643.

24. Franco M, Giusti C, Malieni D, Ferrario D, Galimberti G, Parra İH et l. Síndrome De Sweet Asociado A Neoplasias. Anais Brasileiros De Dermatologia, 2006; 81(5): 473-482

25. Tewarı A, Chandrakumar A, Macdonald D, Staughton R, Bunker CB. Sweet Syndrome Preceding A Carcinoid Lung Tumor And Multiple Myeloma. Cutis, 2013; 92(1): E1-E1.

26. Yamamoto T, Furuse Y, Nishioka K. Sweet's Syndrome With Small Cell Carcinoma Of The Lung. The Journal Of Dermatology, 1994; 21(29): 125-127.

27. Nielsen I, Donati D, Strumia R, Zavarini G, Sartori. Sweet's Syndrome And Malignancy: Report Of The First Case Associated With Adenocarcinoma Of The Lung. Lung Cancer, 1993; 10(12): 95-99.

28. Vrancken A, Verbeken E, Nackaerts K. Skin Lesions İn A Lung Cancer Patient. Acta Clinica Belgica, 2015; 70(3): 231-232.

29. Van Denhove A, Freymond N, Isaac S, Marrou K, Balme B, Gormand F et al. Sweet's Syndrome Associated With Squamous Cell Bronchial Carcinoma. Neutrophilic Dermatosis And NonSmall Cell Lung Cancer. Revue Des Maladies Respiratoires, 2007; 24(1): 77-80.

30. Ahangarı D, Ngendahayo P, Colinet B, Roquet-Gravy PP. Syndrome De Sweet Chez Une Patiente Traitée Par Erlotinib Pour Un Adénocarcinome Bronchique. In: Annales De Dermatologie Et De Vénéréologie. Elsevier Masson, 2020. P. 202-206.

31. Cuny R. Der Fall aus der Praxis (249). Sweet-Syndrom bei Trippelkarzinom [A case from practice (249). Sweet syndrome in triple carcinoma]. Schweiz Rundsch Med Prax. 1992 Aug 25; 81(35): 1030-2.

32. Pelosi G, Papotti M, Rindi G, Scarpa A. Unraveling Tumor Grading And Genomic Landscape İn Lung Neuroendocrine Tumors. Endocrine Pathology, 2014; 25(2): 151-164.

33. Noel-Savina E, Descourt R, Focus On Treatment Of Lung carcinoid tumor. Oncotargets And Therapy, 2013; 6: 1533.

34. Fink G, Krelbaum, Yellin A, Bendayan D, Saute M, Glazer $M$, et al. Pulmonary Carcinoid: Presentation, Diagnosis, And Outcome İn 142 Cases İn Israel And Review Of 640 Cases From The Literature. Chest, 2001; 119(6): 1647-1651. 